\title{
Differential effects of abandonment on the demography of the grassland perennial Succisa pratensis
}

\author{
Sascha van der Meer · Johan Petter Dahlgren • \\ Mikael Mildén · Johan Ehrlén
}

Received: 13 December 2012/ Accepted: 20 August 2013

(C) The Society of Population Ecology and Springer Japan 2013

\begin{abstract}
Abandonment of traditional land-use practices can have strong effects on the abundance of species occurring in agricultural landscapes. However, the precise mechanisms by which individual performance and population dynamics are affected are still poorly understood. To assess how abandonment affects population dynamics of Succisa pratensis we used data from a 4-year field study in both abandoned and traditionally grazed areas in moist and mesic habitats to parameterize integral projection models. Abandoned populations had a lower long-term stochastic population growth rate $\left(\lambda_{\mathrm{S}}=0.90\right)$ than traditionally managed populations $\left(\lambda_{\mathrm{S}}=1.08\right)$, while $\lambda_{\mathrm{S}}$ did not differ between habitat types. The effect of abandonment differed significantly between years and had opposed effects on different vital rates. Individuals in abandoned populations experienced higher mortality rates and lower seedling establishment, but had higher growth rates and produced more flower heads per plant. Population viability analyses, based on a population survey of the whole study area in
\end{abstract}

Electronic supplementary material The online version of this article (doi:10.1007/s10144-013-0400-7) contains supplementary material, which is available to authorized users.

S. van der Meer · J. P. Dahlgren · M. Mildén · J. Ehrlén Department of Ecology, Environment and Plant Sciences, Stockholm University, 10691 Stockholm, Sweden

S. van der Meer $(\bowtie)$

Department of Plant Conservation and Population Biology, University of Leuven, Kasteelpark Arenberg 31, P.O. Box 02435, 3001 Heverlee, Belgium

e-mail: sascha.vandermeer@bio.kuleuven.be

\section{J. P. Dahlgren}

Department of Biology and Max-Planck Odense Center on the Biodemography of Aging, University of Southern Denmark, Campusvej 55, 5230 Odense M, Denmark combination with our demographic models, showed that $32 \%$ of the populations face a high risk of extinction $(>80 \%)$ within 20 years. These results suggest that immediate changes in management are needed to avoid extinctions and further declines in population sizes. Stochastic elasticity analyses and stochastic life table response experiments indicated that management strategies would be most effective if they increase survival of small plants as well as seedling establishment, while maintaining a high seed production. This may be achieved by varying the grazing intensity between years or excluding grazers when plants are flowering.

Keywords Grazing - Integral projection models (IPM) - Management · Population dynamics · Population viability $\cdot$ Stochasticity

\section{Introduction}

Understanding how environmental factors influence the performance, abundance and distribution of species is a central goal in ecology. Similarly, predicting the effects of environmental change on the long-term survival of populations is a key task for population viability analyses (PVA) (Caswell 2001). Today, human-induced changes of the environment, including fragmentation (e.g., Helm et al. 2006) and abandonment of traditional land-use practices like grazing or mowing (e.g., Lehtilä et al. 2006) are considered to constitute major threats to many species. One globally important habitat type that is heavily influenced by human activities is grassland. Most grassland plant species depend on repeated disturbances for their survival (Brys et al. 2004; Auestad et al. 2010). Although disturbances occur naturally, many grasslands in Europe have been 
managed for centuries and have become dependent on human disturbances. Abandonment of traditional land-use practices can therefore be expected to cause grassland species to disappear (Hansson and Fogelfors 2000; Jacquemyn et al. 2003; Johansson et al. 2011). In order to develop effective conservation plans, it is important to understand the mechanisms that cause individual populations to decline and whether mechanisms differ among species, management regimes and habitat types. With such knowledge, we are in a better position to assess overall effects of environmental change and propose management guidelines needed to halt further decline. A mechanistic understanding of population viability can be gained from assessing how vital rates and life-cycle transitions are influenced by specific environmental factors. One of the most powerful approaches involves demographic monitoring and analyses of multiple populations subject to different management regimes over multiple years.

The effect of abandonment of traditional land-use practices on plant species diversity has been well studied (e.g., Cousins and Eriksson 2002; Aptroot et al. 2007) and for several species, demographic responses to such changes have been examined (e.g., Oostermeijer et al. 1996; Lennartsson and Oostermeijer 2001; Brys et al. 2004; Ehrlén et al. 2005; Hamre et al. 2010; Jacquemyn et al. 2012). Abandonment of grassland management has been found to have negative effects on population viability of grassland perennials, while effects of management type (e.g., grazing vs. mowing) are more variable. On the other hand, abandonment can have a positive effect on population viability of highly competitive and productive species (Muller et al. 1998). More studies are needed to determine both the generality of mechanisms, and how they vary among species. Moreover, most plant populations show considerable annual variation in survival, growth and fecundity (Menges 1992). Optimally, studies that examine the magnitude and mechanisms of effects of abandonment or different management practices should thus account for temporal variation in vital rates. Tools to calculate effects of different life cycle transitions and vital rates on population growth in stochastic environments have recently been developed (Rees and Ellner 2009; Caswell 2010; Davison et al. 2010), but have not yet been used to assess the effects of abandonment on population viability.

In this study we examined how abandonment of traditional land-use practices affects the population dynamics of Succisa pratensis, a long-lived perennial herb that is common in semi-natural grasslands in the temperate zones of Europe. In the study area, land-use practices have changed drastically during the last century. Increased agricultural productivity resulted in a smaller total area of crop fields, grazing was moved to the former high-productive crop fields while species-rich semi-natural grasslands that had been managed for centuries were abandoned (Cousins and
Eriksson 2001). After abandonment, many plant populations inhabiting semi-natural grasslands continually decrease in size (Hansson and Fogelfors 2000). This is most likely the result of competitive tall grass and herbaceous species becoming dominant, and an increase in the number of trees and shrubs (Hansson and Fogelfors 2000; Cousins and Eriksson 2001). We conducted a detailed 4-year field study of $S$. pratensis at four sites, which contained abandoned and traditionally grazed populations in two habitat types. We then parameterized both deterministic and stochastic integral projection models (IPMs) for each population, management regime and habitat type, and conducted stochastic elasticity and stochastic life table response experiment (SLTRE) analyses. In addition, we carried out an inventory of 110 populations in the study area and used our models to calculate their respective extinction risk based on population sizes and current management. We asked the following specific questions: (1) Which vital rates benefit from abandonment, which are positively influenced by traditional management, and how do responses differ between years? (2) How do such differences in vital rate responses translate into differences in population viability? (3) Which life-cycle transitions contribute most to differences in population viability? (4) What are the extinction risks of populations in the study area, given current management and population sizes?

\section{Methods}

\section{Study species}

Succisa pratensis Moench (Dipsacaceae) is a polycarpic rosette herb that occurs throughout the temperate zones of Eurasia (Adams 1955) and flowers in August and September. It is self-compatible and produces one to 21 flower heads (mean $=3.2 ; \mathrm{SD}=2.7$ ) on each of up to ten stems, which are about $20-80 \mathrm{~cm}$ in height. Every flower head contains 70-110 pale violet flowers and produced on average $53(\mathrm{SD}=21.5)$ viable seeds in the study area. Reproduction mainly occurs by seeds, but vegetative propagation through side rosettes can take place (Adams 1955; Jongejans and de Kroon 2005) although it was not observed during this study. The life span of genets can be more than 25 years (Hooftman et al. 2003) and S. pratensis has a seed bank which is transient to short-term persistent (McDonald et al. 1996; Wallin et al. 2009).

\section{Study area}

The study was performed between 2000 and 2003 in seminatural grasslands in the northern part of the Nynäs nature reserve $\left(58^{\circ} 50^{\prime} \mathrm{N}, 17^{\circ} 24^{\prime} \mathrm{E}\right)$, situated about $100 \mathrm{~km}$ south of Stockholm, Sweden. Semi-natural grasslands in this region 
can be characterized as unfertilized fodder-producing habitats that were traditionally used for livestock farming (Eriksson et al. 2002). The Nynäs nature reserve is part of the hemiboreal Swedish rural landscape close to the Baltic coast and has undergone important changes in management during the 20th century (Mildén et al. 2007). In Nynäs nature reserve, forest cover has increased from 4 to $17 \%$ since 1945, while the cover of semi-natural grasslands has decreased from 47 to $26 \%$ during the same period (Cousins 2001; Mildén 2005). The abandoned areas are still exposed to natural disturbances. However, this level of disturbance is low and disturbances occur at a very smallscale. A number of semi-natural grassland patches receive management in the form of cattle grazing throughout spring and summer, albeit the grazing pressure is lower than it has been historically.

\section{Data collection}

Four populations of $S$. pratensis were selected for a 4-year detailed demographic study. Two populations were situated in abandoned areas and two in traditionally grazed areas. The selected populations also represented two typical habitat types, moist and mesic (see Herben et al. 2006; Mildén et al. 2006, 2007 for more details), with one abandoned and one traditionally grazed population situated in each of the two habitats. Depending on $S$. pratensis densities at each site, 6-14 permanent plots of $0.25-1 \mathrm{~m}^{2}$ were established. Plots were distributed across the population and were at least $1 \mathrm{~m}$ apart. In each population at least 250 plants with a minimum of 50 flowering individuals were monitored. All plants were mapped using a grid frame with mesh size of $10 \times 10 \mathrm{~cm}$ and were easily found and identified each year. At every visit we recorded the status of each individual (dead or alive), measured the length and width of the largest leaf and documented all new individuals. During flowering, the number of flower heads per plant was recorded. Later in the season up to 30 flower heads per populations were collected outside the permanent plots to estimate the average number of seeds per flower head. To estimate the probability of seed survival in the soil, we conducted a seed sowing experiment. At time of seed ripening in the year 2000 fifty seeds were sown into five or six cleared plots of $10 \times 10 \mathrm{~cm}$ in all studied populations. Plots were visited each of the following 3 years and the numbers of new and surviving seedlings were recorded. Seed survival was calculated from the number of seedlings appearing in each of the 3 years using the following equations

$$
\begin{aligned}
& G_{1}=s_{\text {surv }} s_{\text {est }} \\
& G_{2}=s_{\text {surv }}^{2}\left(1-s_{\text {est }}\right) s_{\text {est }} \\
& G_{3}=s_{\text {surv }}^{3}\left(1-s_{\text {est }}\right)^{2} s_{\text {est }}
\end{aligned}
$$

where $G_{1}, G_{2}$ and $G_{3}$ are the total number of seedlings that were found in 2001, 2002 and 2003, respectively. Assuming that establishment from the soil, $s_{\text {est }}$, was the same in all years, the equations could be solved for $s_{\text {surv }}$. Calculations using this equation and germination data from years 2001-2003 yielded estimates of seed survival of 0.49. Leaf area was calculated as the product of length and width of the largest leaf and was used as a non-destructive estimate of plant size in all subsequent analyses. In total 2,163 individuals, 1,201 in two abandoned and 962 in two traditionally managed populations, were followed during the study. The total population sizes of the abandoned populations were about 900 individuals in both moist and mesic habitat. The total population sizes of the traditionally grazed populations were about 20,000 and 4,000 individuals in moist and mesic habitat, respectively. Additionally, all S. pratensis populations occurring in the northern part of Nynäs nature reserve (total area: $3.1 \mathrm{~km} \times 2.3 \mathrm{~km})$ were documented between 2000 and 2002 (Mildén 2005) and all large vegetative and flowering individuals were counted. A population was defined as a group of S. pratensis individuals that were at least 200 meters apart or situated in distinctly different habitat types. A total of 110 populations were found, 71 of these populations were situated in traditionally grazed habitat and the remaining 39 populations were situated at abandoned sites.

\section{Data analysis}

The effects of plant size, abandonment, habitat, year, and all possible interactions between abandonment, habitat and year on survival, growth, flowering probability, flower heads per plant, seeds per flower head, and seedlings per seed were examined in generalized linear models (GLMs). The models are explained in detail below.

The integrated effect of differences in vital rates of individuals at various stages of the life cycle can be measured by differences in population growth rates. We used IPMs, an alternative to the well-known matrix projection models (e.g., Easterling et al. 2000; Ellner and Rees 2006; Coulson 2012; Metcalf et al. 2013), to estimate population growth rates. IPMs describe how a continuously sizestructured population changes in discrete time (Easterling et al. 2000). In our model, log-transformed size (leaf area) was used as the structuring variable. Population dynamics were described by the size distribution $n(x, t)$, which corresponded to the number of size- $x$ individuals at time $t$. Individuals in the population could survive, grow, and produce new individuals in each time step (year). The function concerning the survival probability of an individual of size $x$ at time $t, s(x)$, was modelled by logistic regression. The growth function, $g(y, x)$, gave the 
probability of an individual growing from size $x$ in year $t$ to size $y$ in year $t+1$ and was modelled as a linear regression of $y$ on $x$. We included a discrete seed bank stage in our model following Ramula et al. (2009). The number of seeds in the seed bank was described by

$$
\begin{aligned}
S(t+1)= & s_{\text {surv }}\left(1-s_{\text {est }}\right) S(t) \\
& +\left(1-s_{\text {est }}\right) \int_{L}^{U} f_{p}(x) f_{\text {heads }} f_{\text {seeds }} n(x, t) d x
\end{aligned}
$$

where $s_{\text {surv }}$ is seed survival and $s_{\text {est }}$ is the probability of establishment of seeds. $s_{\text {est }}$ was assumed to be the same for both establishment from the permanent seed bank and direct establishment from newly produced seeds. To calculate the total number of seeds that could survive and germinate into seedlings in the following year, we first calculated the proportions of seeds in the seed bank and newly produced seeds from the stable size distribution in preliminary models. We used this information together with information about the observed number of newly produced seeds to calculate the number of seeds in the soil seed bank. Finally we calculated the probability of seedling establishment by dividing the total number of seedlings in 1 year by the total number of seeds in the previous year. The fecundity function for the number of seeds produced in one season consisted of the probability of flowering, $f_{p}(x)$, for plants of size $x$, modelled as a logistic regression, multiplied by the mean number of flower heads per plant, $f_{\text {heads }}$, and seeds per flower head, $f_{\text {seeds. }} L$ and $U$ stand for the minimum and maximum possible sizes in the model and these values were set lower and higher than the observed minimum and maximum sizes to avoid unintentional evictions (Williams et al. 2012).

The part of the IPM describing dynamics of established individuals of size $y$ at time $t+1$ was

$$
\begin{aligned}
n(y, t+1) & =s_{\text {est }} f_{\text {size }}(y) S(t)+\int_{L}^{U}[p(y, x)+f(y, x)] n(x, t) d x \\
& =s_{\text {est }} f_{\text {size }}(y) S(t)+\int_{L}^{U} k(y, x) n(x, t) d x
\end{aligned}
$$

The function $k(y, x)$ is known as the kernel. The kernel represents all possible transitions from size $x$ to size $y$ including births and consists of the growth and survival functions $p(y, x)=s(x) g(y, x)$ and a fecundity function $f(y$, $x)=f_{p}(x) f_{\text {heads }} f_{\text {seeds }} s_{\text {est }} f_{\text {size }}(y)$, were $f_{\text {size }}(y)$ describes the probability distribution of seedling size. The vital rate functions, and therefore the whole IPM, could be constructed for any kind of grouped data like population, management regime, year, or habitat type.
We calculated $100 \times 100$ matrices representing the continuous transition kernels. We then used these matrices to calculate the asymptotic population growth rate (dominant eigenvalue) and the stable stage distribution (dominant right eigenvector), using the package 'popbio' in R (Stubben and Milligan 2007). All population growth rates were bootstrapped using the $\mathrm{R}$ package 'boot', to obtain confidence intervals. Individuals were randomly sampled with replacement, the re-sampled data was then used to construct a new matrix and calculate $\lambda$, and this process was repeated 10,000 times. After confirmation that the distribution of $\lambda$ was approximately normal, the $95 \%$ confidence intervals were calculated using the 'basic' bootstrap method in the 'boot.ci' function. Population growth rates based on the IPMs with a linear growth function were also compared to population growth rates calculated using IPMs with a non-linear growth function, based on a five-knot restricted cubic spline regression, because the relationships between plant sizes for two consecutive years were slightly non-linear in some cases. The differences observed among the models with linear growth functions were approximately the same when non-linear growth functions were used. Yet, there were some differences; for data pooled over years, management regimes and habitat types $\lambda$ was 0.01 higher in the model with a non-linear growth function, and in the IPM for the abandoned plots (pooled over years and habitat types) $\lambda$ was 0.02 higher with a non-linear growth function.

Stochastic population growth rates $\left(\lambda_{\mathrm{S}}\right)$ were calculated for abandoned and traditionally managed sites by randomly selecting one of three annual matrices for the respective management type with equal probability for each of 10,000 model iterations, and taking the geometric mean of the obtained annual growth rates (Caswell 2001; Morris and Doak 2002).

Stochastic elasticity analyses were performed to determine which changes in life-cycle transitions would have a large effect on $\lambda_{\mathrm{s}}$. Mean- and standard deviationelasticity values were calculated by perturbing each nonzero matrix element so that either the mean or the standard deviation over the 3 years was affected, and the average proportional effect on growth rate was calculated from 25,000 model iterations for each matrix element and type of perturbation (cf. Tuljapurkar et al. 2003). Stochastic mean-elasticity values measure the proportional sensitivity of $\lambda_{\mathrm{S}}$ to changes in mean transition rates. Stochastic SD-elasticity values measure the proportional sensitivity of $\lambda_{\mathrm{S}}$ to changes in variability. Elasticities were summed across regions of the matrix to be able to compare fecundity to growth and survival elasticities (Silvertown et al. 1993). In order to determine what caused the observed differences in growth rate between 
abandoned and grazed sites, we also performed SLTRE analyses following Davison et al. (2010). Effects of differences in vital rates were calculated in terms of contributions of both differences in means and standard deviations to differences in $\lambda_{\mathrm{S}}$. SLTRE contributions of differences in means of vital rates were calculated by first summing up the total stochastic mean-elasticities for vital rates affecting multiple matrix elements, from analyses on yearly average matrices, and then multiplying these elasticities with the log ratio of the mean vital rates for the two types of environment. Corresponding analyses were then done for standard deviations in vital rates. The basic SLTRE function is (Eq. 1 in Davison et al. 2010):

$$
\begin{aligned}
\lambda_{\mathrm{S}}^{A}-\lambda_{\mathrm{S}}^{G} \approx & \sum_{i j}\left[\log \mu_{i j}^{(A)}-\log \mu_{i j}^{(G)}\right] E_{i j}^{\mu} \\
& +\sum_{i j}\left[\log \sigma_{i j}^{(A)}-\log \sigma_{i j}^{(G)}\right] E_{i j}^{\sigma}
\end{aligned}
$$

where $A$ is abandoned, $G$ is grazed and $E$ is the stochastic elasticity. All analyses were done in R 2.12.0 (R Development Core Team 2012).

We also used our stochastic models to evaluate the risk of extinction for all 110 existing populations based on size and management regime, as in Morris and Doak (2002). The quasi-extinction threshold was set to $\leq 5$ adult plants and extinction probabilities were calculated for 20 and 50 years as the proportion of 1,000 model iterations where the quasi-extinction threshold was reached. The starting vector for each population was based on observed number of above-ground individuals in 2002, while the number of seeds in the seed bank was estimated using the proportion of the stable stage distribution constituted by seeds in the soil seed bank for the abandoned and traditionally managed matrices, respectively.

\section{Results}

Vital rates

All vital rates were size dependent and several were significantly affected by abandonment, but no vital rates differed between habitat types (Table 1). In addition, all vital rates were affected by year or the interaction between abandonment and year. Plants growing at abandoned sites had lower survival probabilities (mean $=0.55$; $\mathrm{SD}=0.59)$ than plants at traditionally managed sites (mean $=0.89 ; \mathrm{SD}=0.31$, Fig. 1a). However, the size of the effect of abandonment on survival differed between years, and was largest in 2002-2003 (Table 1; Fig. 1a).

In contrast to the negative effects on survival, abandonment had a positive effect on growth of large vegetative and flowering individuals (Fig. 1b, c). In accordance, the average size of adult plants in abandoned populations was higher (mean $=8.0 ; \mathrm{SD}=8.2$ ) than in traditionally managed populations $($ mean $=7.3 ; \mathrm{SD}=7.0$ ). The magnitude of the effects of abandonment on size differed among years (Table 1), and was highest during 2000-2001.

Abandonment did not have a significant effect on the probability of flowering at a given size (Table 1; Fig. 1d), but flowering plants at abandoned sites produced significantly more flower heads per plant (mean $=4.4 ; \mathrm{SD}=3.2$ ) than flowering plants at traditionally managed sites $($ mean $=1.6 ; \quad \mathrm{SD}=0.9)$. The average seed production per flower head did not differ significantly between abandoned and traditionally managed populations. The probability of seedling establishment (per seed) at abandoned sites was on average lower (0.010) than seedling establishment at traditionally managed sites (0.022).

Table 1 Effect of plant size, abandonment, habitat, year, and all possible interactions between abandonment, habitat and year on survival,

\begin{tabular}{|c|c|c|c|c|c|c|}
\hline & \multicolumn{6}{|c|}{ Vital rates } \\
\hline & Survival & Growth & $\begin{array}{l}\text { Flowering } \\
\text { probability }\end{array}$ & $\begin{array}{l}\text { Number of flower } \\
\text { heads }\end{array}$ & $\begin{array}{l}\text { Seeds per flower } \\
\text { head }\end{array}$ & $\begin{array}{l}\text { Seedlings per } \\
\text { seed }\end{array}$ \\
\hline Plant size & $* * *$ & $* * *$ & $* * *$ & $* * *$ & NA & NA \\
\hline Abandonment & $* * *$ & $* * *$ & - & $* * *$ & - & $* *$ \\
\hline Habitat & - & - & - & - & - & - \\
\hline Year & - & $* * *$ & $* * *$ & - & $*$ & $*$ \\
\hline Abandonment $\times$ Habitat & - & - & - & - & - & - \\
\hline Abandonment $\times$ Year & $* * *$ & $* * *$ & - & $* * *$ & - & $* *$ \\
\hline Habitat $\times$ Year & - & - & - & - & - & - \\
\hline Abandonment $\times$ Habitat $\times$ Year & - & - & - & - & - & - \\
\hline
\end{tabular}
growth, flowering probability, flower heads per plant, seeds per flower head, and seedlings per seed in the perennial herb Succisa pratensis

The abbreviation NA indicates that data was not available

Significance codes: $* * * P<0.001, * * P<0.01, * P<0.05$ and ${ }^{-} P>0.05$ 
Fig. 1 Vital rate functions, for abandoned (solid lines) and traditionally managed (dotted lines) populations, in 2000-2001 (black), 2001-2002 (dark gray), and 2002-2003 (light gray). a Logistic regression of the survival probability from year $t$ to year $t+1$ over individual size at time $t$. b Linear regression of size at year $t+1$ over size at year $t$, for abandoned populations in 2000-2001, 2001-2002, and 2002-2003 and the pooled annual data for traditionally managed populations (dotted black line). c Linear regression of size at year $t+1$ over size at year $t$, for traditionally managed populations in 2000-2001, 2001-2002, and 2002-2003 and pooled annual data for abandoned populations (solid black line). d Logistic regression of the flowering probability of individuals of different sizes
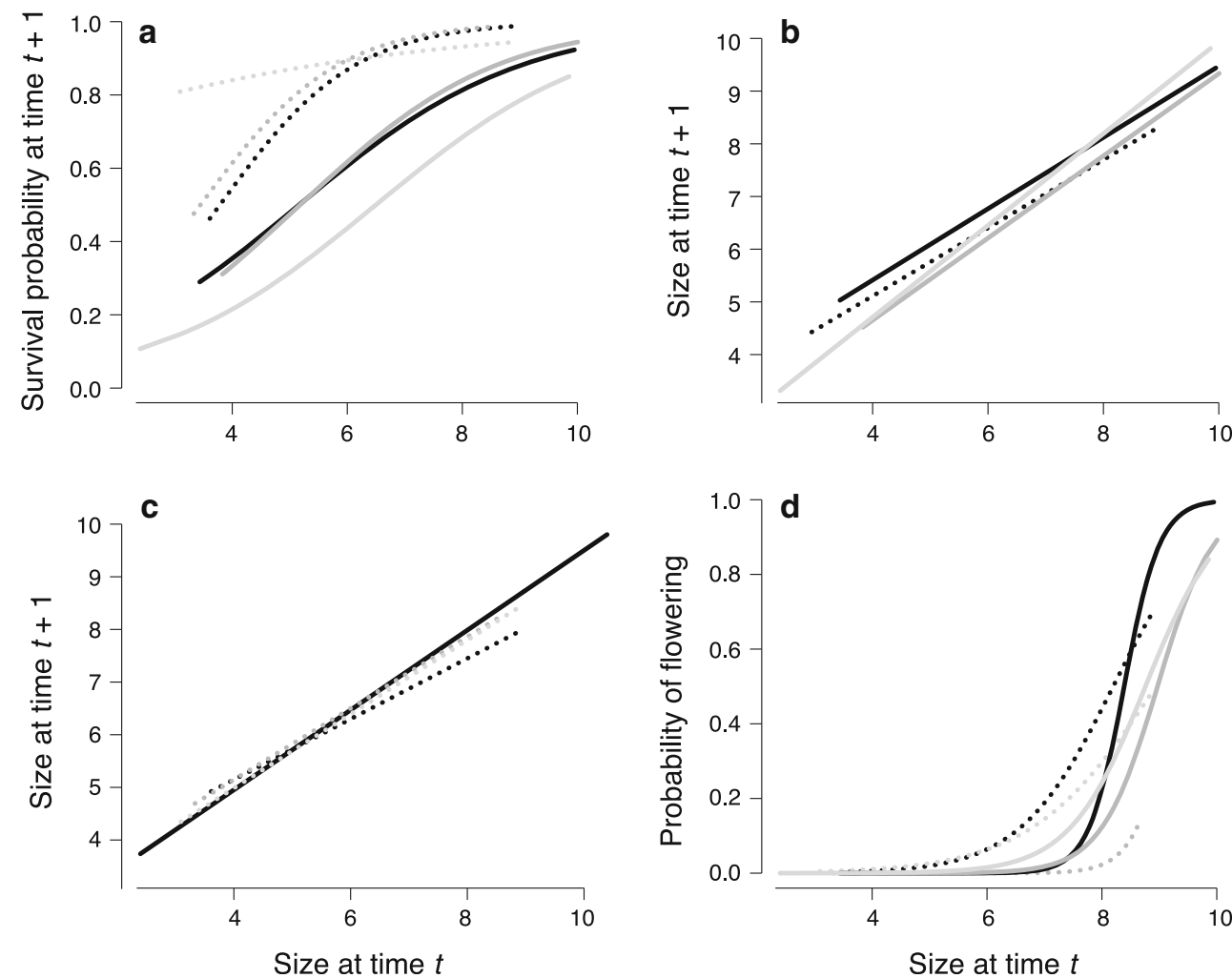

Table 2 Deterministic population growth rates $(\lambda)$ for three transition intervals and stochastic population growth rates for abandoned versus traditionally managed populations

\begin{tabular}{lll}
\hline & Abandoned & Traditionally managed \\
\hline 2000-2001 & $0.999(0.948-1.058)$ & $0.958(0.930-0.987)$ \\
$2001-2002$ & $0.874(0.820-0.923)$ & $1.131(1.049-1.303)$ \\
$2002-2003$ & $0.870(0.810-0.954)$ & $1.054(1.025-1.085)$ \\
Stochastic $\lambda$ & 0.901 & 1.079 \\
\hline
\end{tabular}

Values of $95 \%$ confidence intervals of deterministic growth rates, based on 10,000 bootstrap replicates, are given within parentheses

Population growth rate

Differences in vital rates between abandoned and traditionally managed sites and years caused differences in population growth rates (Table 2). Mean population growth rates of moist and mesic habitats (data pooled over years and management regimes) had overlapping confidence intervals. The deterministic growth rate of the mean matrix for abandoned populations across years and sites was 0.904 suggesting an overall decline in population size of almost $10 \%$ per year. For traditionally managed populations $\lambda$ of the mean matrix was 1.082 across years and sites, suggesting a yearly increase in population size. Population growth rates varied substantially between years, but stochastic growth rates for abandoned and traditionally managed populations were only slightly lower than deterministic rates of the mean matrix, 0.901 and 1.079 respectively (Table 2 ).

Stable size distribution

The stable size distribution of established plants at abandoned sites was relatively even among size classes (Fig. 2a), but $94 \%$ of individuals were seeds in the seed bank. The stable size distribution of traditionally managed populations was dominated by medium-sized individuals (Fig. 2b) and had a smaller proportion of seeds in the seed bank $(68 \%)$.

Stochastic elasticity analysis

Stochastic mean-elasticity values for reproduction (i.e., seed production and seedling establishment) were lower in abandoned than in traditionally managed populations (Fig. 3). Summed reproduction elasticities for abandoned and traditionally managed populations (0.13 and 0.20 respectively), were lower than summed survival-growth elasticities (0.87 and 0.80 respectively). We also found large differences in summed survival-growth elasticities for different size classes. Elasticities of small plants (first half of the size classes minus the seed class) were 0.22 in abandoned populations and 0.58 in traditionally managed populations and elasticities of large plants were 0.65 and 0.21 respectively. Thus, changes in survival-growth 


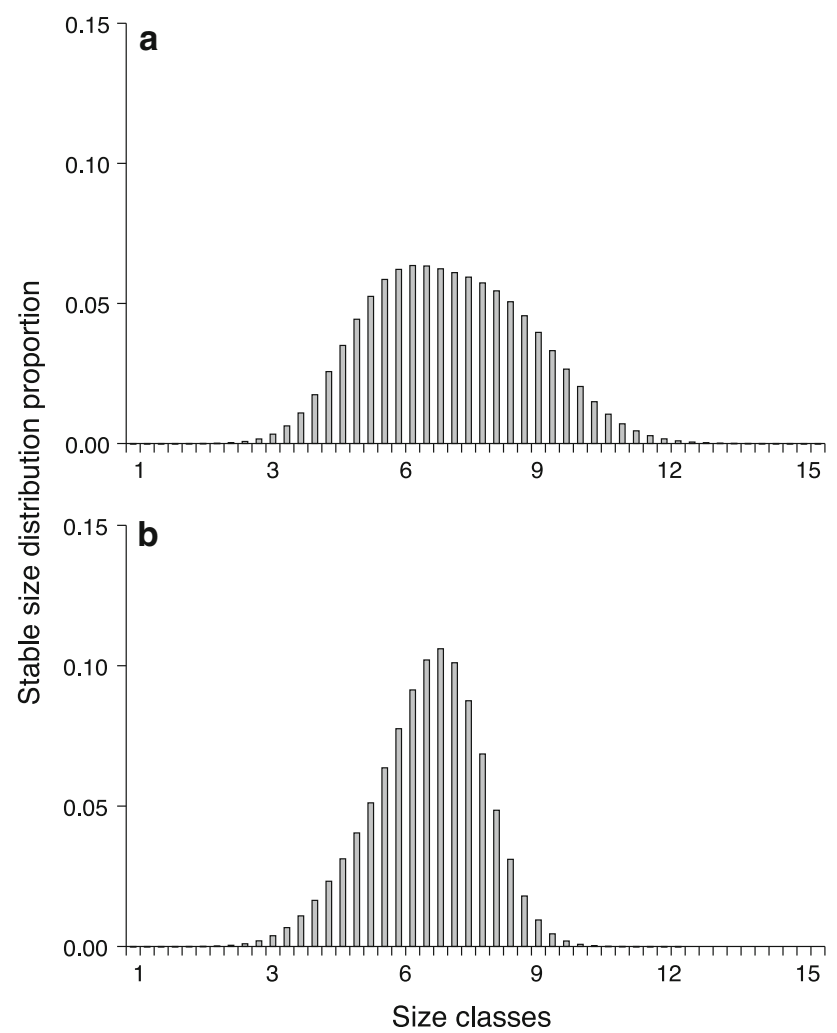

Fig. 2 The stable size distribution, without seed bank, of Succisa pratensis in a abandoned and $\mathbf{b}$ traditionally managed populations, represented using 50 equally wide size classes and their corresponding plant sizes

transitions of large plants would have a larger effect on population growth in abandoned than in traditionally managed populations while changes in survival-growth transitions of small plants would be relatively more important in traditionally managed populations. Overall SD-elasticities were very close to zero (data not shown), suggesting that variation in vital rates had a relatively small effect, which is in accordance with the small differences between average deterministic and stochastic population growth rates. Additionally, vital rate elasticity analysis showed that survival and growth had similar stochastic elasticity values (S1 in the Electronic Supplementary Material, ESM).

Stochastic life table response experiment

SLTRE analysis showed that lower survival of especially small plants and lower rates of seedling establishment contributed most to the lower $\lambda_{\mathrm{S}}$ in abandoned populations (Fig. 4). Growth and the number of seeds produced to the seed bank were higher in abandoned populations, but this was not sufficient to outweigh the negative effects of survival and seedling establishment.
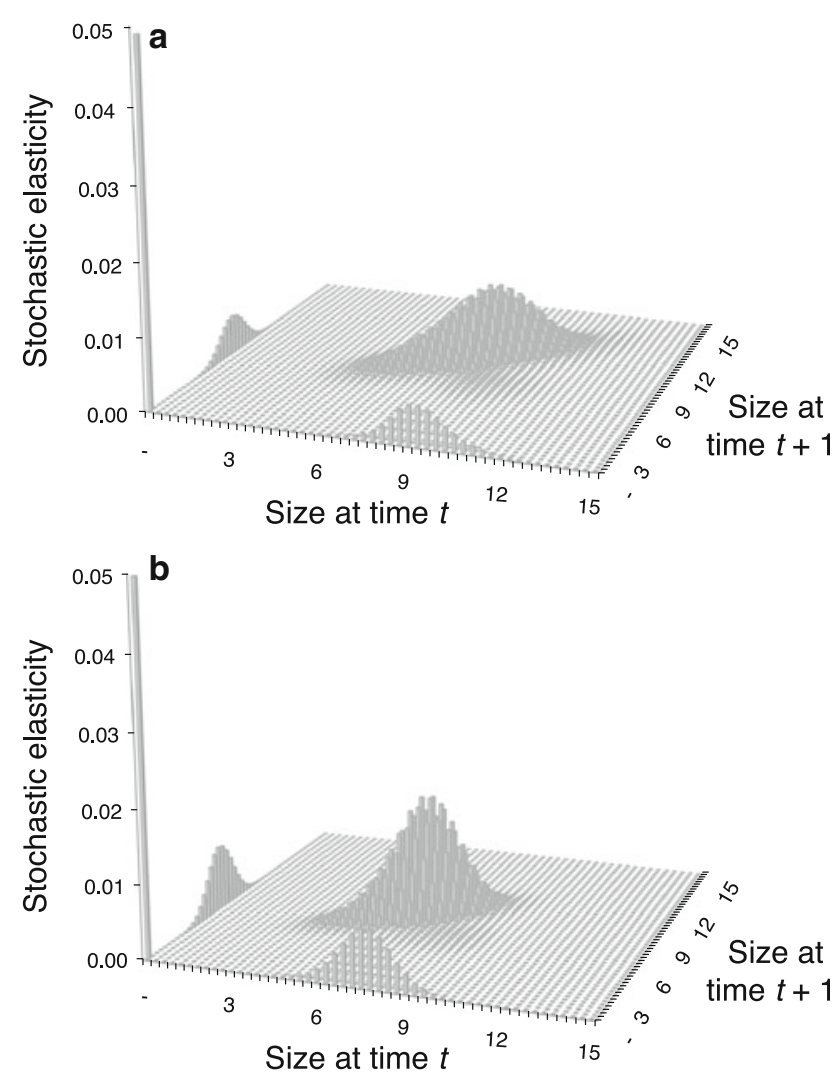

Fig. 3 Stochastic mean-elasticity values of $\mathbf{a}$ abandoned and $\mathbf{b}$ traditionally managed sites for plants of all sizes. The first class is denoted '-' and refers to seeds, the remaining classes are size classes starting from 1. The peak on the first axis (size at time $t$ ) shows seed production elasticities, seedling establishment elasticities are shown in the first class on the second axis (size at time $t+1$ ). The transition for seeds that stay in the seed bank is shown in the first class of both axes

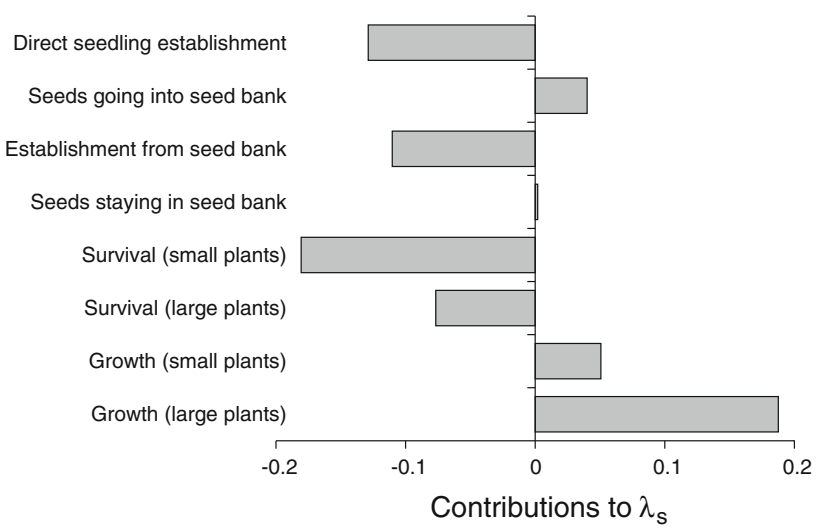

Fig. 4 Results of the SLTRE decomposition of vital rate contributions to differences in $\lambda_{\mathrm{S}}$ between abandoned and traditionally managed populations. Values for survival and growth transitions of non-seedling individuals were summed over plant sizes corresponding to the first and second half of the size classes, respectively 


\section{Extinction risk}

Of the 110 populations of $S$. pratensis surveyed between 2000 and 2002, 39 were situated at abandoned sites and 71 in traditionally managed areas. Eight small populations, six abandoned and two traditionally managed, went extinct between 2000 and 2002, hence 102 populations remained. The 33 abandoned populations ranged in size from 2 to 4,821 individuals in 2002 and had an average and median population size of $247(\mathrm{SD}=847)$ and 20 individuals, respectively. The largest traditionally managed population contained more than 20,000 individuals, but the average and median population size was $1,116(\mathrm{SD}=3,266)$ and 62 individuals, respectively. At abandoned sites we found 4 populations with 5 or fewer adult individuals and these were assumed likely to go extinct within 20 years due to stochastic processes. Our models showed that 24 additional abandoned populations face a considerable risk of extinction $(>80 \%)$ within 20 years and most populations, 29 out of 33 , face the same risk within 50 years. Only the largest population had a negligible extinction risk within this timeframe. At the managed sites, 9 out of 69 populations already contained 5 or fewer adult individuals. All other populations at traditionally grazed sites face no risk of extinction according to our models (i.e., will not reach populations sizes of five or fewer individuals).

\section{Discussion}

In this study we showed that the overall effect of abandonment of traditional land-use practices on the performance of Succisa pratensis was negative, but this effect varied among both vital rates and years. Habitat type, however, did not have a significant effect on any of the vital rates. Abandonment positively affected growth of large plants and seed production, but negatively affected survival and seedling establishment. Vital rates differed significantly between years, but this variation had a relatively small effect on predicted long-term population growth rates. Stochastic population growth rates were below 1 in abandoned populations and above 1 in traditionally managed populations. This difference in growth rates was mainly the result of lower seedling establishment and higher mortality rates of small plants in abandoned plots. Combining our detailed demographic data with information on all $S$. pratensis populations in the study area suggest that $32 \%$ of these populations face a higher than $80 \%$ risk of extinction within 20 years, mostly due to abandonment of traditional management practices.

Abandonment of traditional land-use practices had negative effects on seedling establishment while the effects on vital rates of established individuals varied. Negative effects on seedling establishment have also been found in Primula veris (Brys et al. 2004), Carex davalliana (Billeter et al. 2003) and Succisella inflexa (Overbeck et al. 2003). Traditional grazing, in turn, had positive effects on seedling establishment of several grassland perennials (Oesterheld and Sala 1990; Lennartsson and Oostermeijer 2001; Brys et al. 2004). In the current study, seedling establishment was up to twice as high in traditionally managed as in abandoned populations. Seed production in abandoned populations of $S$. pratensis was higher due to increased fruit production. Billeter et al. (2003) have also shown that seed production of $S$. pratensis was significantly higher in abandoned as in managed populations. Contrary to our results they found higher seedling densities at abandoned sites. They, however, did not calculate seedling establishment per seed nor long-term population growth rates, thus the overall effect of abandonment was unknown. Besides having a positive effect on seed production, we also found a positive effect of abandonment on growth, particularly in adult plants. In the absence of large herbivores plants can obtain larger sizes, since vegetative structures are less damaged by grazing and trampling. This effect was expected and might be a general effect across species (Hilbert et al. 1981). Furthermore, survival rates of $S$. pratensis were lower at abandoned sites, an effect that has been shown in P. veris as well (Brys et al. 2004). Our results, in combination with results from other study systems, suggest that abandonment can have a positive effect on growth of adult plants and increase seed production, but the overall effect on population viability may be negative because of reduced seedling establishment and survival.

Populations at abandoned sites had a mean growth rate below unity, while traditionally grazed sites favoured the persistence of $S$. pratensis populations. Wallin and Svensson (2012) also studied traditionally managed populations of $S$. pratensis in Sweden and found similar $\lambda_{\mathrm{S}}$ values as in grazed populations in the current study. Additionally, they found that reinforced raking and mowing increased $\lambda_{\mathrm{S}}$ further. Negative effects of abandonment on population growth have been found in more grassland species. Abandoned $P$. veris populations in Belgium had a $\lambda$ below 0.85 (Brys et al. 2004). When $P$. veris populations are managed, in terms of late summer grazing, cutting of surrounding vegetation or mowing with litter removal, population growth rates are higher and mostly close to or above 1 (Brys et al. 2004; Ehrlén et al. 2005). Other forms of management such as mulching or cutting can also increase $\lambda$ of grassland plants in comparison to abandonment (Schleuning and Matthies 2008; Hamre et al. 2010). Apart from competition with other herbs and grasses, canopy closure as a result of abandonment can lead to decreased population growth rates due to a lack of light on the ground (Lehtilä et al. 2006). In general, abandonment 
of management has been shown to have a negative effect on population growth of many grassland plants, justifying its status as a major conservation issue in large parts of Europe.

Differences in vital rates between abandoned and traditionally managed populations did not contribute equally to differences in population growth. Lower seedling establishment and survival of mainly small individuals caused lower growth rates in abandoned populations. Jongejans and de Kroon (2005) also modelled population dynamics of $S$. pratensis and found that low $\lambda$ values at sites with unsuitable management were caused by lower fecundity transitions. In the current study, fecundity transitions had larger relative decreases but survival contributed roughly equally to the negative effect of abandonment on population growth due to high elasticity values. The probability of flowering and growth showed significant annual variation and the effect of abandonment on survival and growth differed significantly between years as well. The processes that drive these annual variations are unknown, although local climate conditions probably explain a part of the observed temporal variation. It may be worth noting that the year 2000-2001 had high average precipitation (measured at the Stockholm/Nyköping weather station; Diebel and Norda 2013). During this year the probability of flowering was highest in both abandoned and traditionally managed populations. Abandoned populations also had relatively high population growth rates that year. However, further studies with a high number of annual transitions are needed to analyze correlations between demographic processes and drivers of annual variation.

The majority of populations in the study area situated at traditionally managed sites (60 out of 69) are likely to persist within a foreseeable future. However, 32 out of 33 populations at abandoned sites face considerable extinction risks according to our models. These results illustrate how $S$. pratensis, and possibly many other grassland perennial herbs, are likely to face a rapid loss of populations after abandonment and underscore the need for appropriate management. Our results suggest that an optimal scenario for the conservation of perennials in semi-natural grasslands may be a management regime where the intensity of management varies among years. Two years of intense management could create favourable conditions for recruitment and survival, while in the subsequent year the management intensity could be lowered to allow for high seed production. Prohibiting management action when plants are flowering could also be an option. Both strategies aim to increase seedling establishment, survival and growth of especially small plants while maintaining high seed production.
In conclusion, we have demonstrated that abandonment can affect different vital rates in opposite ways and differentially among years. Therefore, the results of this study show that IPMs in combination with stochastic elasticity analyses and SLTRE can be used to gain a more mechanistic understanding of the effect of abandonment on species viability. Moreover, we suggest that combining data from detailed demographic studies with a large number of similar populations in the study area is important to get a better picture of the viability not only on the population level, but on a regional level as well.

Acknowledgments This study was supported by EU project TRANSPLANT (EVK2-CT-1999-00004) and an ERASMUS Placement Scholarship from the University of Amsterdam. We would like to thank Jelle S. van Zweden, Gerard Oostermeijer, Hans Jacquemyn and two reviewers for comments that improved the manuscript.

\section{References}

Adams AW (1955) Succisa pratensis Moench. J Ecol 43:709-718 Aptroot A, Dobben HF, Slim PA, Olff H (2007) The role of cattle in maintaining plant species diversity in wet dune valleys. Biodivers Conserv 16:1541-1550

Auestad I, Rydgren K, Jongejans E, de Kroon H (2010) Pimpinella saxifraga is maintained in road verges by mosaic management. Biol Conserv 143:899-907

Billeter R, Hooftman DAP, Diemer M (2003) Differential and reversible responses of common fen meadow species to abandonment. Appl Veg Sci 6:3-12

Brys R, Jacquemyn H, Endels P, Blust GD, Hermy M (2004) The effects of grassland management on plant performance and demography in the perennial herb Primula veris. J Appl Ecol 41:1080-1091

Caswell H (2001) Matrix population models: construction, analysis, and interpretation. Sinauer Associates, Sunderland

Caswell H (2010) Life table response experiment analysis of the stochastic growth rate. J Ecol 98:324-333

Coulson T (2012) Integral projections models, their construction and use in posing hypotheses in ecology. Oikos 121:1337-1350

Cousins SAO (2001) Analysis of land-cover transitions based on 17th and 18th century cadastral maps and aerial photographs. Landsc Ecol 16:41-54

Cousins SAO, Eriksson O (2001) Plant species occurrences in a rural hemiboreal landscape: effects of remnant habitats, site history, topography and soil. Ecography 24:461-469

Cousins SAO, Eriksson O (2002) The influence of management history and habitat on plant species richness in a rural hemiboreal landscape, Sweden. Landsc Ecol 17:517-529

Davison R, Jacquemyn H, Adriaens D, Honnay O, de Kroon H, Tuljapurkar S (2010) Demographic effects of extreme weather events on a short-lived calcareous grassland species: stochastic life table response experiments. J Ecol 98:255-267

Diebel J, Norda J (2013) WeatherSpark. http://weatherspark.com/

Easterling MR, Ellner SP, Dixon PM (2000) Size-specific sensitivity: applying a new structured population model. Ecology 81:694-708

Ehrlén J, Syrjänen K, Leimu R, Garcia MB, Lehtilä K (2005) Land use and population growth of Primula veris: an experimental demographic approach. J Appl Ecol 42:317-326 
Ellner SP, Rees M (2006) Integral projection models for species with complex demography. Am Nat 167:410-428

Eriksson O, Cousins SAO, Bruun HH (2002) Land-use history and fragmentation of traditionally managed grasslands in Scandinavia. J Veg Sci 13:743-748

Hamre LN, Rydgren K, Halvorsen R (2010) The effects of mulching and abandonment on the viability of the perennial grassland species Plantago lanceolata. Plant Ecol 211:147-158

Hansson M, Fogelfors H (2000) Management of a semi-natural grassland; results from a 15-year-old experiment in southern Sweden. J Veg Sci 11:31-38

Helm A, Hanski I, Pärtel M (2006) Slow response of plant species richness to habitat loss and fragmentation. Ecol Lett 9:72-77

Herben T, Münzbergová Z, Mildén M, Ehrlén J, Cousins SAO, Eriksson O (2006) Long-term spatial dynamics of Succisa pratensis in a changing rural landscape: linking dynamical modelling with historical maps. J Ecol 94:131-143

Hilbert DW, Swift DM, Detling JK, Dyer MI (1981) Relative growth rates and the grazing optimization hypothesis. Oecologia $51: 14-18$

Hooftman DAP, van Kleunen M, Diemer M (2003) Effects of habitat fragmentation on the fitness of two common wetland species, Carex davalliana and Succisa pratensis. Oecologia 134:350-359

Jacquemyn H, Brys R, Hermy M (2003) Short-term effects of different management regimes on the response of calcareous grassland vegetation to increased nitrogen. Biol Conserv 111:137-147

Jacquemyn H, Brys R, Davison R, Tuljapurkar S, Jongejans E (2012) Stochastic LTRE analysis of the effects of herbivory on the population dynamics of a perennial grassland herb. Oikos 121:211-218

Johansson VA, Cousins SAO, Eriksson O (2011) Remnant populations and plant functional traits in abandoned semi-natural grasslands. Folia Geobot 46:165-179

Jongejans E, de Kroon H (2005) Space versus time variation in the population dynamics of three co-occurring perennial herbs. J Ecol 93:681-692

Lehtilä K, Syrjanen K, Leimu R, Garcia MB, Ehrlén J (2006) Habitat change and demography of Primula veris: identification of management targets. Conserv Biol 20:833-843

Lennartsson T, Oostermeijer JGB (2001) Demographic variation and population viability in Gentianella campestris: effects of grassland management and environmental stochasticity. J Ecol $89: 451-463$

McDonald AW, Bakker JP, Vegelin K (1996) Seed bank classification and its importance for the restoration of species-rich floodmeadows. J Veg Sci 7:157-164

Menges ES (1992) Stochastic modeling of extinction in plant populations. In: Fiedler PL, Jain SK (eds) Conservation biology: the theory and practice of nature conservation, preservation, and management. Chapman and Hall, New York, pp 253-275

Metcalf CJE, McMahon SM, Salguero-Gómez R, Jongejans E (2013) IPMpack: an R package for integral projection models. Method Ecol Evol 4:195-200
Mildén M (2005) Local and regional dynamics of Succisa pratensis. Ph.D. Thesis. Stockholm University, Sweden

Mildén M, Münzbergová Z, Herben T, Ehrlén J (2006) Metapopulation dynamics of a perennial plant, Succisa pratensis, in an agricultural landscape. Ecol Model 199:464-475

Mildén M, Cousins SAO, Eriksson O (2007) The distribution of four grassland plant species in relation to landscape history in a Swedish rural area. Ann Bot Fenn 44:416-426

Morris WF, Doak DF (2002) Quantitative conservation biology: theory and practice of population viability analysis. Sinauer Associates, Sunderland

Muller S, Dutoit T, Alard D, Grévilliot F (1998) Restoration and rehabilitation of species-rich grassland ecosystems in France: a review. Restor Ecol 6:94-101

Oesterheld M, Sala OE (1990) Effects of grazing on seedling establishment: the role of seed and safe-site availability. J Veg Sci 1:353-358

Oostermeijer JGB, Brugman ML, de Boer ER, den Nijs HCM (1996) Temporal and spatial variation in the demography of Gentiana pneumonanthe, a rare perennial herb. J Ecol 84:153-166

Overbeck G, Kiehl K, Abs C (2003) Seedling recruitment of Succisella inflexa in fen meadows: importance of seed and microsite availability. Appl Veg Sci 6:97-104

Ramula S, Rees M, Buckley YM (2009) Integral projection models perform better for small demographic data sets than matrix population models: a case study of two perennial herbs. J Appl Ecol 46:1048-1053

R Development Core Team (2012) R: a language and environment for statistical computing. http://www.r-project.org/

Rees M, Ellner SP (2009) Integral projection models for populations in temporally varying environments. Ecol Monogr 79:575-594

Schleuning M, Matthies D (2008) Habitat change and plant demography: assessing the extinction risk of a formerly common grassland perennial. Conserv Biol 23:174-183

Silvertown J, Franco M, Pisanty I, Mendoza A (1993) Comparative plant demography-relative importance of life-cycle components to the finite rate of increase in woody and herbaceous perennials. J Ecol 81:465-476

Stubben C, Milligan B (2007) Estimating and analyzing demographic models using the popbio package in R. J Stat Softw 22:1-23

Tuljapurkar S, Horvitz CC, Pascarella JB (2003) The many growth rates and elasticities of populations in random environments. Am Nat 162:489-502

Wallin L, Svensson BM (2012) Reinforced traditional management is needed to save a declining meadow species. A demographic analysis. Folia Geobot 47:231-247

Wallin L, Svensson BM, Lönn M (2009) Artificial dispersal as a restoration tool in meadows: sowing or planting? Restor Ecol $17: 270-279$

Williams JL, Miller TEX, Ellner SP (2012) Avoiding unintentional eviction from integral projection models. Ecology 93:2008-2014 